\title{
AVALIAÇÃO DE DIFERENTES ROTAS DE ESFOLIAÇÃO LÍQUIDA PARA OBTENÇÃO DE NANOLAMELAS DE NITRETO DE BORO HEXAGONAL
}

\author{
Mayara Regina Munaro ${ }^{a, b}$, Heloisa Nunes da Motta ${ }^{a}$, Joseane V. Gulmine ${ }^{a}$, Luciane Tulio ${ }^{a}$, Nuno G. Adonis ${ }^{c}$, Marilda \\ Munaro $^{\mathrm{a}, \mathrm{b}, *}$ e Edemir Luiz Kowalski ${ }^{\mathrm{a}, \mathrm{b}}$ \\ a'Departamento de Elétrica e Materiais, Instituto de Tecnologia para o Desenvolvimento, Caixa Postal 19067, 81531-990 Curitiba \\ - PR, Brasil

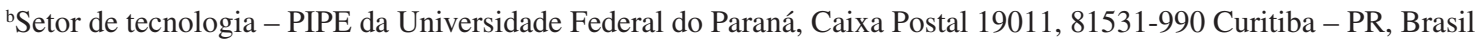 \\ ${ }^{\mathrm{c} C}$ Companhia Paranaense de Energia, Rua José Izidoro Biazetto, 158 Bairro Mossunguê - CEP 81200-240 - Curitiba - PR, Brasil
}

Recebido em 27/03/2017; aceito em 25/07/2017; publicado na web em 15/09/2017

\begin{abstract}
EVALUATION OF DIFFERENT ROUTES OF LIQUID EXFOLIATION FOR THE OBTENTION OF HEXAGONAL BORON NITRIDE NANOSHEETS. Hexagonal boron nitride (h-BN), graphite analogous structure, has many interesting applications due to its excellent thermal, electrical and mechanical properties. In this study, different routes of liquid exfoliation using solvent and ultrasound were used to obtain two-dimensional (2D) nanosheets of h-BN. The efficiency of the exfoliative routes was evaluated by Transmission electron microscopy (TEM) and UV-Vis spectroscopy. Results demonstrated that the technique was effective in the exfoliation of h-BN bulk and that the solvent's choice, considering an optimum surface tension of the solvent-solute system, and the rotation of the centrifugation in the selection of the exfoliated nanosheets, are crucial for the performance of the technique. The most promising exfoliation route has been found to be the dispersion of $\mathrm{h}-\mathrm{BN}$ in solvent mixture (20\% IPA in water) for $3 \mathrm{~h}$ on ultrasound, followed by centrifugation at 1500 or $3000 \mathrm{rpm}$.
\end{abstract}

Keywords: hexagonal boron nitride; liquid exfoliation; nanosheets; layered materials.

\section{INTRODUÇÃO}

Materiais lamelares bidimensionais têm sido muito estudados devido à riqueza de fenômenos físicos incomuns que ocorrem quando o transporte de carga e calor são confinados em um plano. $\mathrm{O}$ confinamento de elétrons possibilita propriedades eletrônicas muito atraentes e a espessura atômica oferece maior flexibilidade mecânica e transparência óptica. ${ }^{1-5}$ Além disso, a elevada área superficial em relação ao seu volume garante elevados níveis de energia na superfície, sendo extremamente atraente para a transferência de calor, ${ }^{5,6}$ além de propiciar estruturas altamente sensíveis a estímulos, tais como modificação química, campos elétricos, deformação mecânica, dopagem e adsorção de outras moléculas ou materiais, permitindo maior controle e ajuste dessas propriedades. ${ }^{1,3-5}$

Entre os materiais bidimensionais, o nitreto de boro hexagonal (h-BN) apresenta excelente resistência mecânica e à corrosão, alta resistividade elétrica, elevada dureza e condutividade térmica estimada entre 300 a $2000 \mathrm{Wm} \mathrm{K}^{-1}$. $^{6-10}$ Além de ser altamente inerte, atóxico e possuir ação lubrificante, ${ }^{6-10}$ sua forma cristalina hexagonal é semelhante à do grafite, em que camadas bidimensionais (2D) alternadas de átomos de boro $(\mathrm{B})$ e nitrogênio $(\mathrm{N})$, vinculadas por ligações covalentes em um arranjo tipo "colmeia", são sobrepostas e ligadas por fracas forças de van der Waals, formando um cristal anisotrópico tridimensional (3D)..$^{7-9}$

A principal vantagem do nitreto de boro em relação ao grafite é a sua estabilidade térmica. ${ }^{7,10}$ Além disso, é um material isolante elétrico com elevada condutividade térmica, propriedades interessantes para a aditivação de compósitos dielétricos e dispositivos eletro e optoeletrônicos, ${ }^{2,6-10}$ obtidas preferencialmente a partir da exposição dos planos (002) do cristal. ${ }^{4,6}$ Dessa forma, o processo de separação por meio da esfoliação facilita a exposição desses planos e a exploração do material. ${ }^{4,6}$

\footnotetext{
*e-mail: marilda@lactec.org.br
}

A esfoliação ou delaminação é uma técnica capaz de romper as forças de van der Waals entre as estruturas lamelares bidimensionais (2D). ${ }^{3}$ As lamelas produzidas são geralmente referidas como nanolamelas, onde "nano" refere-se à magnitude da espessura..$^{2-4} \mathrm{~A}$ partir do sucesso na obtenção de uma única camada de grafite, tem sido estimulado o interesse em outros materiais lamelares, como dicalcogenetos de metais de transição (TMDs), óxidos metálicos, argilas e outros compostos, ${ }^{1-5,8,11}$ sendo o grafeno e o nitreto de boro hexagonal os materiais lamelares mais simples. ${ }^{2,3,7,12}$ Embora a estrutura geral e os espaçamentos atômicos de ambos sejam muito semelhantes, materiais de nitreto de boro $(\mathrm{BN})$ possuem interações mais fortes entre suas camadas devido à diferença de eletronegatividade de seus átomos, dificultando a separação das lamelas. ${ }^{6-10,13,14}$

Inúmeros métodos sintéticos vêm sendo desenvolvidos para a obtenção de uma ou poucas camadas de nanolamelas de BN, tanto em qualidade quanto em quantidade, podendo ser divididos em processos químicos (bottom-up) ou físicos (top-down). ${ }^{1,2,4,8-11} \mathrm{Os}$ métodos químicos são baseados em reações e utilizam precursores moleculares ou atômicos para a obtenção das nanopartículas desejadas. São bem difundidos por se tratarem de técnicas mais eficazes e possibilitarem maior controle sobre o processo, tais como deposição de vapor químico (CVD) e crescimento epitaxial. No entanto, essas técnicas requerem condições de crescimento severas, como elevada temperatura e alto vácuo, possuem limitação na produção de nanolamelas em quantidade, ${ }^{1,5,11,14}$ necessitam de reagentes químicos e a diferença térmica entre o substrato (superfície aquecida onde o filme é depositado) e o filme favorece a presença de falhas e de impurezas devido ao processamento, ${ }^{8,15}$ aumentando a complexidade e o custo dos processos. ${ }^{1,9-11,16,17}$

Os métodos físicos manipulam o material em escala macro e por meio de técnicas como clivagem micromecânica, intercalação iônica, esfoliação líquida, fragmentam as partículas até que estas fiquem em escala nanométrica. ${ }^{1,6,8,11,13-15}$ Oferecem vantagens em relação às rotas químicas devido à redução de custos, compatibilidade térmica com o 
substrato - em relação ao método CVD, simplicidade e versatilidade, juntamente com o fato de que resultam em nanolamelas esfoliadas de alta qualidade que podem ser facilmente transformadas em filmes finos e (ou) aditivadas em materiais compósitos. ${ }^{1,3,4,9-11,16,17}$ Entretanto, não há muito controle do número e do tamanho lateral das lamelas, o rendimento é baixo e é preciso ter atenção com solventes tóxicos, de difícil remoção ou que possam reagir no processo. ${ }^{1,8,9}$

Dentre os métodos físicos, a esfoliação líquida em solvente expõe o material lamelar a ondas ultrassônicas que, por meio da cavitação, geram ondas de energia que colapsam e fragmentam os cristais lamelares, produzindo nanolamelas esfoliadas..$^{1-4,6,8-11,13-25}$ É um processo insensível ao ar e não envolve reações químicas, fatores que melhoram a processabilidade, além de manter as propriedades intrínsecas dos materiais., ${ }^{411,16,17}$ Apresenta escalabilidade para a produção de uma grande variedade de (ou praticamente qualquer) nanomaterial bidimensional. $3,4,11$

A eficiência do processo esfoliativo está vinculada à otimização de três parâmetros essenciais: a escolha do solvente; o tempo e potência de ultrassom; e o tempo e rotação de centrifugação. No ultrassom, o processo de cavitação é capaz de separar as lamelas de h-BN da estrutura 3D em dispersão devido às interações entre as moléculas de solvente e a superfície das partículas. ${ }^{11,15,18} \mathrm{O}$ tempo de ultrassonificação é importante para o rendimento e minimização dos danos nas nanolamelas separadas e varia conforme o tipo de material, solvente, potência do equipamento e, ainda, finalidade do processo. Alguns autores utilizaram longos tempos de ultrassonificação, como 10 a 168 horas, ${ }^{4,15,18-20}$ e outros, tempos reduzidos, variando de 30 minutos a 8 horas. ${ }^{4,6,13,14,16,21-28} \mathrm{Niu}$ et al. salientaram que longos tempos geram concentrações mais elevadas de nanolamelas em dispersão, contudo, tanto as dimensões das lamelas são reduzidas, de acordo com o inverso da raiz quadrada do tempo $\left(\mathrm{t}^{-1 / 2}\right)$, quanto defeitos em bordas e arestas são induzidos. ${ }^{11}$ Além disso, dispersões ultrassonificadas sempre contêm algum cristal não esfoliado. ${ }^{23,27}$

O tamanho da partícula de h-BN pode ter importante impacto sobre a eficiência da esfoliação, ${ }^{15}$ quanto maior a partícula inicial, menor será o rendimento da técnica. ${ }^{13}$ Porém, o uso de partículas iniciais maiores não conduz, necessariamente, a nanolamelas com maior área superficial. ${ }^{13}$ Além disso, a concentração de nanolamelas esfoliadas depende da quantidade de energia fornecida durante a ultrassonificação, sendo que banhos ultrassônicos de baixa potência resultam em dispersões com menores concentrações de material lamelar em comparação com o ultrassom de ponta. ${ }^{28}$ A estratégia de utilizar o banho ultrassônico seguido de ultrassom de ponta pode ser eficaz na obtenção de suspensões mais estáveis. ${ }^{28}$ Todavia, alguns autores salientaram que a distribuição de tamanho das nanolamelas geradas pela esfoliação não depende dos diferentes métodos de preparo utilizados, indicando que a técnica possui um comprimento de escala típico para nanolamelas, comum na esfoliação deste tipo de material e, provavelmente, de outros materiais $2 \mathrm{D} .^{20}$

Além do tempo e potência do ultrassom, a escolha do solvente é crucial porque a energia superficial das nanolamelas cria uma tensão interfacial que deve ser superada para afastar as partículas, mantê-las separadas e evitar aglomerações. . $^{1,3,4,9,11,14,18,21,23,25}$ Dessa forma, se a energia de superfície do solvente for semelhante à do material, a diferença de energia entre os estados esfoliados e reagregados será menor, reduzindo a força de atração entre as lamelas e estabilizando-as na dispersão. ${ }^{3,4,14,21}$ Parâmetros de solubilidade também podem ser utilizados para melhor entender e caracterizar o fenômeno que ocorre entre material disperso e dispergente ou, de forma análoga, entre soluto e solvente, pois a obtenção de uma solução requer grande afinidade entre ambos. ${ }^{4,11,16,21,23-25}$

Muitos solventes têm sido investigados para a dispersão e esfoliação do h-BN em ultrassom, tais como álcool isopropílico
(IPA), ${ }^{4,6,10,14,19-21,24} \mathrm{~N}, \mathrm{~N}$-dimetil-formamida (DMF), ${ }^{18}$ ácido metanossulfónico, ${ }^{9}$ dimetilsulfóxido (DMSO) ${ }^{4} \mathrm{~N}$-metil-pirrolidona (NMP), ${ }^{3,4,13}$ dispersantes como a solução de poli(m-fenileno vinileno-co-2,5-dioctoxi-p-fenileno vinileno) em 1,2-dicloroetano, ${ }^{27}$ moléculas de amina lipofílicas ou hidrofílicas, ${ }^{26}$ bases de Lewis ou líquidos iônicos. ${ }^{22,26}$ Para o h-BN, o álcool isopropílico é favorecido devido, principalmente, a sua tensão superficial (30-40 $\left.\mathrm{mJ} \mathrm{m}^{-2}\right)$ minimizar a energia de esfoliação, apresentando maior concentração de material esfoliado após a centrifugação. ${ }^{4,6,10,11,14,15,21,25}$ Isso sugere que o h-BN possui energia superficial de $65 \mathrm{~mJ} \mathrm{~m}^{-2}$, pois a energia de superfície do IPA é, aproximadamente, $30 \mathrm{~mJ} \mathrm{~m}^{-2}$ maior que a sua tensão superficial, como argumentado por Coleman et al. ${ }^{4}$ fazendo com que as energias de superfícies do soluto e solvente sejam equivalentes. Este valor tem correspondência com a faixa de energias de superfície estimadas para materiais de $\mathrm{BN}\left(44-66 \mathrm{~mJ} \mathrm{~m}^{-2}\right){ }^{4,29}$

Para melhorar a dispersão e esfoliação do h-BN existem tentativas bem sucedidas de combinar dois ou mais solventes durante a ultrassonificação, como etanol e água, ${ }^{14-16,21,24}$ que, além da tensão superficial, consideram o tamanho das moléculas da mistura, sugerindo que moléculas maiores de solvente servem para estabilizar as lamelas individualmente dispersas de forma mais eficaz, evitando que elas se agreguem novamente. ${ }^{14,21}$ Em estudo avaliando a eficiência da esfoliação por espectroscopia no UV-Vis, Marsh et al. mostraram que as dispersões de h-BN em IPA apresentaram a máxima absorbância na concentração de $40 \%$ de solvente em água, correspondendo a uma tensão superficial de $25 \mathrm{~mJ} \mathrm{~m}^{-2} .^{14}$

A centrifugação das dispersões é importante na seleção das nanolamelas esfoliadas, sendo que quanto maior a rotação de centrifugação, menor a espessura e o tamanho médio das nanolamelas e vice-versa. ${ }^{13,18,30}$ Foi observado que rotações de centrifugação mais baixas (500-2000 rpm) resultam em lamelas com maior número de camadas. ${ }^{30}$

Considerando os principais parâmetros na técnica de esfoliação líquida, o presente trabalho teve como objetivo explorar diferentes rotas de esfoliação líquida do h-BN, variando-se o solvente, o uso combinado de ultrassom de banho e de ponta, esfoliação individual e simultânea de amostras e a rotação da centrifugação com o intuito de obter um processo otimizado, com maior rendimento, para obtenção de nanolamelas bidimensionais de nitreto de boro.

\section{PARTE EXPERIMENTAL}

\section{Materiais}

Foram utilizados nitreto de boro hexagonal em pó (98\% de pureza, partícula $\sim 1 \mu \mathrm{m}$ ) da Sigma Aldrich; álcool isopropílico (IPA) da Carlo Erba (densidade de $0,785 \mathrm{~g} / \mathrm{ml}$ a $20^{\circ} \mathrm{C}$ ) e água deionizada pelo Purificador de água Merck-Millipore Milli-Q Plus (modelo Direct 8). As esfoliações foram realizadas em balões volumétricos de fundo redondo de $250 \mathrm{~mL}$.

\section{O método de esfoliação líquida do h-BN}

As dispersões foram preparadas com concentração inicial em massa de $0,1 \%$ de h-BN em solvente e esfoliadas durante $3 \mathrm{~h}$ no ultrassom da Eco-Sonics (modelo Q9.5/37 A, $37 \mathrm{KHz}$ ). Em seguida, foram centrifugadas no equipamento da Sigma (modelo 4-16S) durante 30 minutos em 1500 rotações por minuto, tendo como resultado um precipitado composto de material pouco esfoliado e um sobrenadante. O sobrenadante (fração superior da dispersão) foi coletado e quantificado por meio da absorbância no espectro UV-Vis e pela pesagem do material esfoliado, após evaporação do solvente. O precipitado foi utilizado em mais dois processos de esfoliação, como ilustra a Figura 1. 


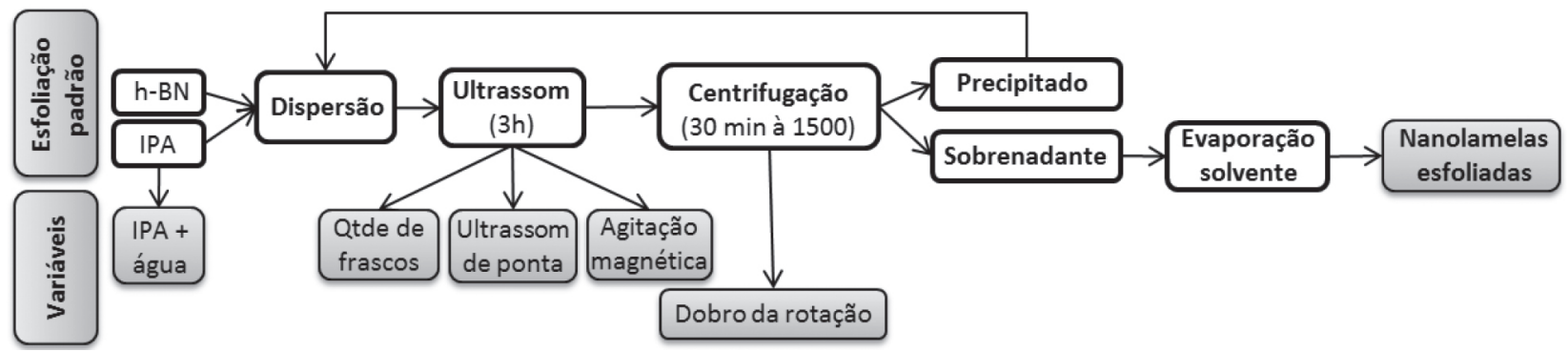

Figura 1. Esquema do processo padrão de esfoliação do h-BN e as variáveis adotadas no método

Além do processo de esfoliação padrão, foram avaliados a influência da quantidade de frascos simultâneos no ultrassom durante a esfoliação, o uso combinado de ultrassom de ponta e de banho, a mistura de solventes (álcool isopropílico - água deionizada) considerando a tensão superficial ótima, o aumento da rotação de centrifugação e a utilização da agitação magnética intercalada com o ultrassom. O conjunto amostral analisado se encontra na Tabela 1.

No processo padrão individual (PI) a amostra foi esfoliada colocando-se um balão por vez no banho ultrassônico e, no sistema simultâneo (PS), foram colocados três balões juntos. Com a variável ultrassom de ponta (UP), a dispersão foi submetida a 15 min da sonda ultrassônica Omni, modelo Sonic Ruptor 400, a 160 W de potência, em seguida foi ultrassonificada no banho por 3 horas. Nos processos com agitação magnética (AM), a cada hora de ultrassom a amostra foi submetida a 30 min de agitação a $1500 \mathrm{rpm}$ no agitador magnético da Quimis (modelo 0261M12).

\section{Ensaios realizados}

As medidas de tensão superficial das misturas de solventes foram realizadas no tensiômetro digital da Kruss, modelo K10ST.

O microscópio da Tescan, modelo Vega 3, foi utilizado nas imagens de microscopia eletrônica de varredura (MEV) da amostra de h-BN em pó inicial. Concomitantemente, algumas áreas das imagens foram submetidas à análise de mapeamento químico semi-quantitativo por espectroscopia por dispersão de energia de raios X (EDS). O granulômetro a laser da Cilas, modelo 1064, foi empregado no ensaio de distribuição granulométrica desse material, na faixa de 0,04 a 500 $\mu \mathrm{m}$, e o agente dispersante foi o álcool isopropílico.

As esfoliações foram caracterizadas por imagens de microscopia eletrônica de transmissão (MET) no equipamento da JEOL-JEM 1200 EX-II, com tensão de $120 \mathrm{kV}$, e comparadas com o h-BN não esfoliado (micrométrico). No preparo da amostra, o h-BN não esfoliado foi diluído em IPA e uma alíquota dessa dispersão foi depositada em uma grade de cobre coberta por um filme ultrafino de carbono da Ted Pella, com posterior evaporação do solvente em condições ambiente. Uma alíquota dos sobrenadantes resultantes de cada amostra esfoliada também foi preparada dessa forma.

Os espectros de absorção no UV-Vis dos sobrenadadantes foram obtidos no Espectrofotômetro da Agilent, modelo Cary 60, utilizando cubetas de quartzo de $1 \mathrm{~cm}$. Foram preparadas curvas de calibração nas duas bases de solvente (IPA e 20\% IPA) pela dispersão de $6 \mathrm{mg}$ de nanolamelas de BN - medidas na balança analítica do Analisador termogravimétrico da Netzsch (modelo TG 209 F3 Tarsus) com precisão de 3 casas decimais em miligramas - com $100 \mathrm{~mL}$ de solvente, durante $3 \mathrm{~h}$ no ultrassom. Essas dispersões foram diluídas em diferentes concentrações volumétricas e caracterizadas no UV-Vis para relacionar a intensidade das absorbâncias no UV-Vis com a concentração das amostras, no comprimento de onda de $400 \mathrm{~nm} .^{4,14}$ A pesagem do material esfoliado seco, após volatização do solvente, foi realizada na balança Analítica da Shimadzu (modelo AX200) com precisão de 4 casas decimais em gramas.

\section{RESULTADOS E DISCUSSÃO}

\section{Caracterização do h-BN}

Na Figura 2 está apresentada a imagem obtida por MEV e a análise química por EDS das partículas de h-BN antes da esfoliação. Notase que as micropartículas apresentaram formato típico do material, com configuração geométrica circular, como pequenos discos, com dimensões variadas, e no espectro de raios X (EDS) foram observados dois picos bem definidos correspondentes aos átomos de boro (B) e nitrogênio $(\mathrm{N})$, equivalendo a 99,9\% da estrutura analisada, indicando a pureza do material utilizado.

A Figura 3 apresenta a distribuição granulométrica das micropartículas de h-BN. O histograma representa a porcentagem acumulada das partículas em cada classe granulométrica da amostra analisada

Tabela 1. Relação dos parâmetros experimentais adotados na técnica de esfoliação líquida do h-BN

\begin{tabular}{|c|c|c|c|c|c|c|}
\hline \multirow{2}{*}{ Amostra } & \multirow{2}{*}{ Sigla } & \multirow{2}{*}{ Solvente } & \multicolumn{2}{|c|}{ Agitação magnética } & \multicolumn{2}{|c|}{ Centrifugação } \\
\hline & & & Tempo (h) & Rot. (rpm) & Tempo (min) & Rot. (rpm) \\
\hline Padrão individual & PI & IPA & - & - & 30 & 1500 \\
\hline Padrão simultâneo & PS & IPA & - & - & 30 & 1500 \\
\hline Ultrassom de ponta & UP & IPA & - & - & 30 & 1500 \\
\hline Mistura IPA:água & MS & $20 \%$ IPA & - & - & 30 & 1500 \\
\hline Dobro de centrifugação & DC & IPA & - & - & 30 & 3000 \\
\hline Mist. IPA:água+dobro centrif. & MSD & $20 \%$ IPA & - & - & 30 & 3000 \\
\hline Agitação magnética & $\mathbf{A M}$ & IPA & $1,5 \mathrm{~h}$ & 1500 & 30 & 1500 \\
\hline Mist. IPA:água+agitação & MSA & $20 \%$ IPA & $1,5 \mathrm{~h}$ & 1500 & 30 & 1500 \\
\hline Mist. IPA:água+agitação+dobro cent. & MAD & $20 \%$ IPA & $1,5 \mathrm{~h}$ & 1500 & 30 & 3000 \\
\hline
\end{tabular}


(a)

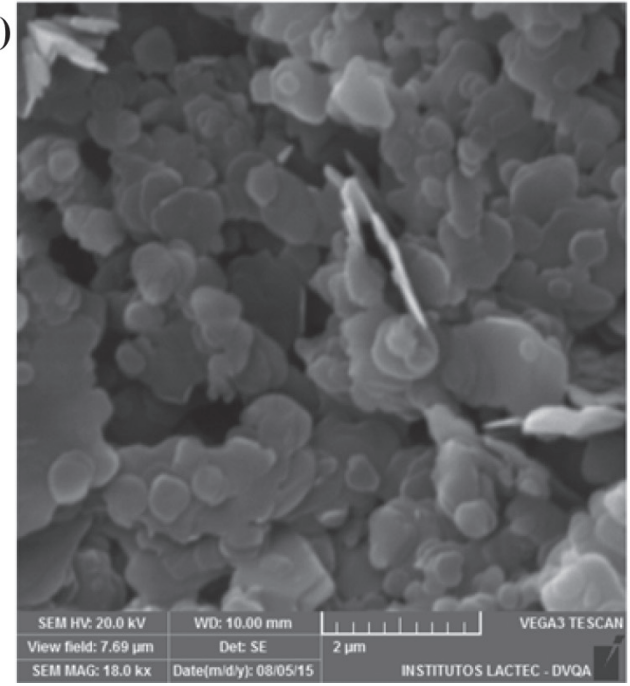

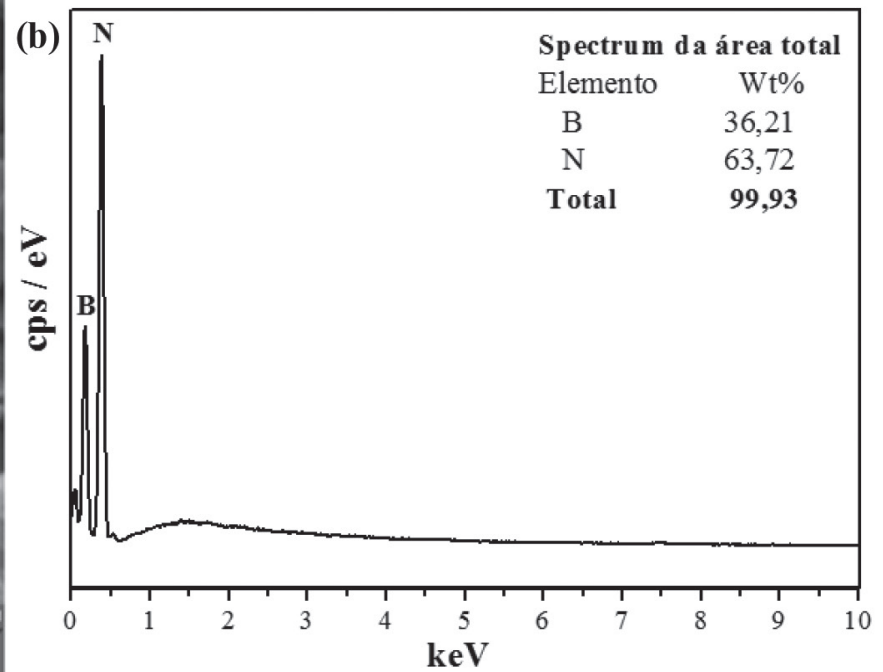

Figura 2. Caracterização do h-BN micrométrico em MEV. (a) Imagem MEV do h-BN adquirido comercialmente; (b) espectro EDS do h-BN com tabela de discriminação dos elementos analisados

e, a curva, o valor percentual da soma de frequências acumuladas. Observa-se que o material apresentou partículas menores de 0,04 até $10 \mu \mathrm{m}$, com maior concentração na faixa de 3 a $5 \mu \mathrm{m}$ e dimensão média de $3 \mu \mathrm{m}$, o que corrobora com a variação de tamanho observada na imagem de MEV.

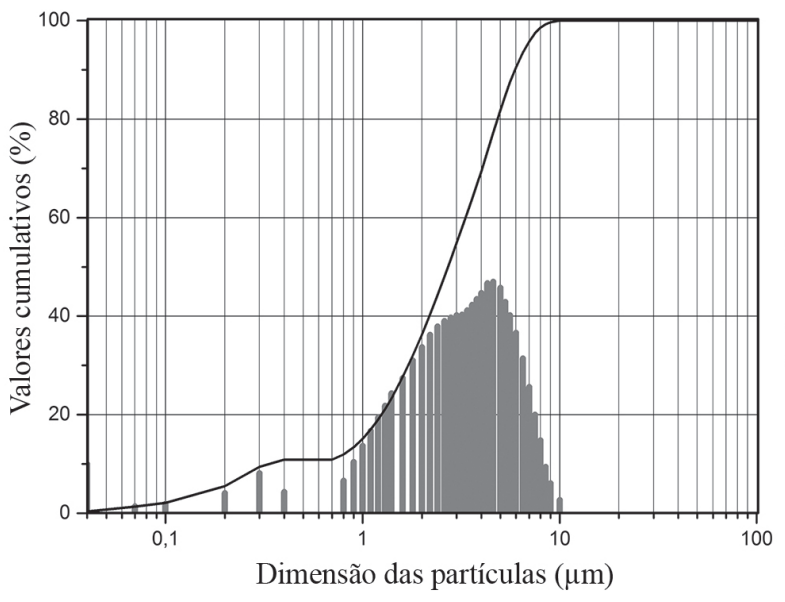

Figura 3. Distribuição granulométrica das micropartículas de $h-B N$

\section{Definição da concentração de IPA e água}

A fim de se obter a concentração mais adequada de álcool isopropílico com água deionizada foram avaliadas as tensões superficiais de concentrações mássicas de 0 a $100 \%$ de IPA em água, em intervalos de $10 \%$. A Figura 4 apresenta os valores médios de tensão superficial obtidos para essas misturas. O álcool isopropílico apresentou tensão superficial de $22,0 \mathrm{~mJ} \mathrm{~m}^{-2}$ e a água deionizada de $70,3 \mathrm{~mJ} \mathrm{~m}^{-2}$. Os valores de tensão superficial indicados para os sistemas de solventes, na esfoliação líquida do h-BN, variaram entre 25 a $40 \mathrm{~mJ} \mathrm{~m}{ }^{-2}{ }^{4,14,21,25}$ Esses valores foram observados nas concentrações de 10 a $50 \%$ de IPA em água. Como o valor mais recorrente utilizado na literatura foi de $30 \mathrm{~mJ} \mathrm{~m}^{-2}, 4,21$ foram adotadas as concentrações de $20 \%\left(31,6 \mathrm{~mJ} \mathrm{~m}^{-2}\right)$ e $30 \%\left(27,7 \mathrm{~mJ} \mathrm{~m}^{-2}\right)$ de IPA em água para a realização de esfoliações líquidas do h-BN.

Os sobrenadantes das esfoliações obtidos com as concentrações de $20 \%$ e $30 \%$ de IPA em água foram avaliados por meio da absorbância no UV-Vis e comparados com o sobrenadante da

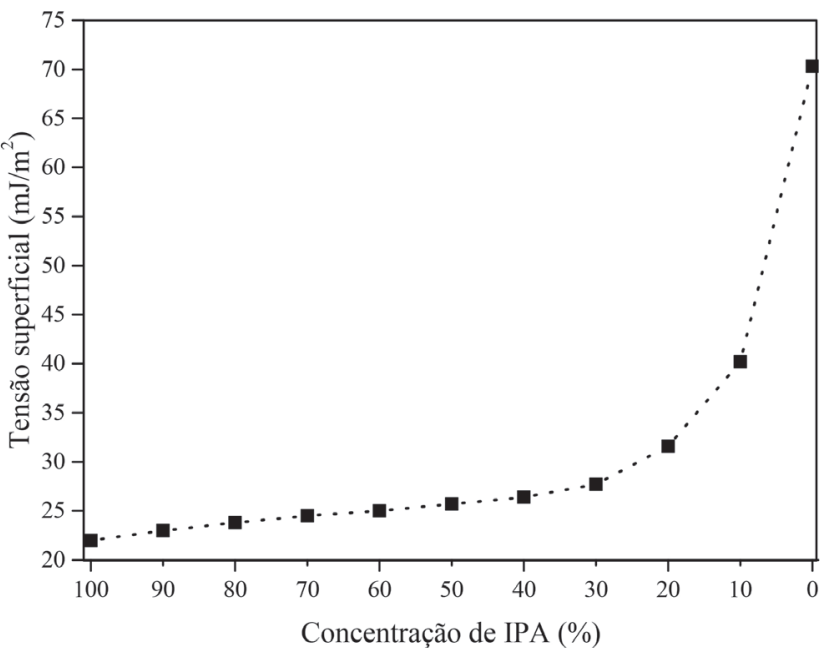

Figura 4. Tensão superficial das misturas de álcool isopropílico (IPA) em água deionizada

esfoliação utilizando somente o IPA como solvente, como apresenta a Figura 5. O álcool isopropílico e a água deionizada foram utilizados como linhas base nas medidas e foi observado que a curva com maior absorbância correspondeu à dispersão esfoliada com a mistura de 20\% de IPA em água, obtendo, aproximadamente, $20 \%$ de aumento na absorbância, em comparação com as outras duas bases de solvente. Nos espectros de absorbância UV-Vis, quanto maior o deslocamento da curva em relação à linha base, maior é a absorbância da amostra, ou seja, maior é a quantidade de partículas em suspensão., ${ }^{4,14}$ Com esse resultado, a concentração de $20 \%$ de IPA em água foi adotada na variável mistura de solventes (MS) na esfoliação líquida do nitreto de boro.

\section{Avaliação das esfoliações líquidas de h-BN}

A Figura 6 apresenta as caracterizações no MET de cada processo esfoliativo em comparação ao h-BN não esfoliado. O h-BN não esfoliado apresenta micropartículas dispostas desordenadamente e com diferentes graus de empilhamento. Mesmo que a imagem exiba lamelas com poucas camadas foi evidenciado, majoritariamente, partículas com várias camadas sobrepostas. As imagens das amostras esfoliadas (Figura 6, b-j) apresentaram nanolamelas bidimensionais 


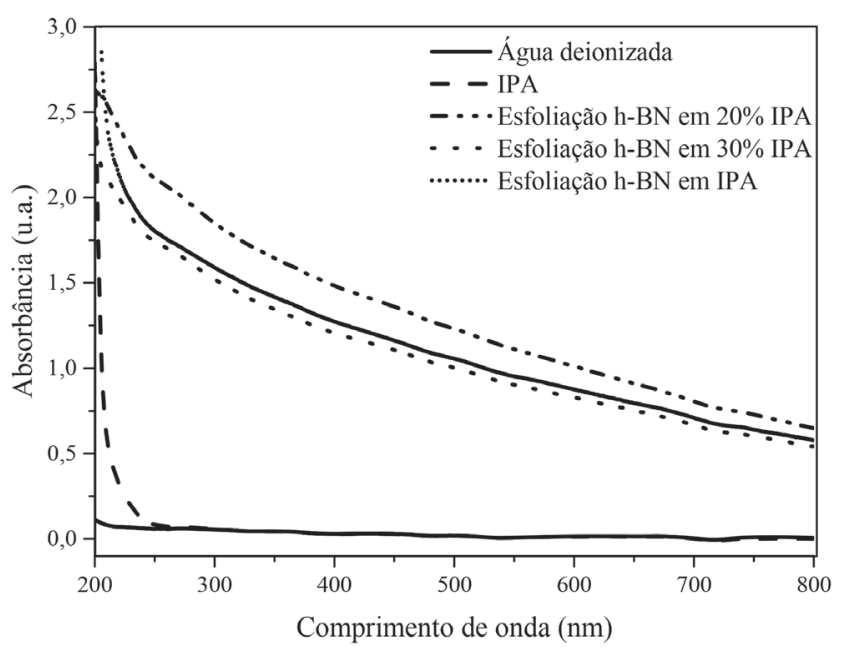

Figura 5. Espectros de absorbância no UV-Vis das esfoliações líquidas do $h$-BN realizadas nas três bases de solvente: álcool isopropílico (IPA) e nas misturas de $20 \%$ e $30 \%$ de IPA em água

também dispostas desordenadamente umas sobre as outras. Os diferentes graus de empilhamento lamelar evidenciam que os sobrenadantes obtidos foram formados pela suspensão de mono e poucas camadas de nanolamelas de h-BN. Em geral, as imagens apresentaram lamelas com dimensões médias de $500 \mathrm{~nm}$, sem fraturas e defeitos e com bordas e arestas bem definidas.

O grau de esfoliação das dispersões foi evidenciado pela variação das tonalidades das cores cinza e preto das nanolamelas: quanto mais clara a cor, menor o número de camadas empilhadas da lamela e vice-versa. Foram notadas quantidades não significativas de material não esfoliado, ressaltado pelos pontos escuros e opacos de algumas imagens (lamelas com grande número de camadas perfeitamente empilhadas) e evidência de lamelas individuais em todas as amostras esfoliadas.

As amostras esfoliadas obtidas com a variável dobro de centrifugação (Figura 6 - f, g, j) apresentaram menor quantidade de material e de regiões escuras e lamelas com dimensões laterais reduzidas, devido à seleção das partículas menores e mais esfoliadas com o aumento da rotação. As imagens das demais rotas esfoliativas não apresentaram diferença significativa, indicando que os parâmetros adotados não alteraram de forma expressiva a obtenção das nanolamelas de $\mathrm{BN}$.

A fim de obter uma comparação quantitativa das dispersões esfoliadas, uma alíquota de cada sobrenadante foi medida quanto à absorbância no UV-Vis e, por meio de curvas de calibração, foi possível estimar a quantidade de material disperso nas diluições. A Figura 7 apresenta as curvas de calibração nas duas bases de solvente (IPA e mistura de solventes), relacionando a absorbância com a quantidade de nanolamelas de $\mathrm{BN}$ dispersas.

Por meio dessas curvas de calibração, foram calculadas as quantidades mássicas e os rendimentos obtidos nas diferentes rotas esfoliativas. Esses valores estão apresentados na Tabela 2, juntamente com os valores mássicos obtidos pela evaporação do solvente e pesagem do material esfoliado. Observa-se que as dispersões esfoliadas de h-BN apresentaram diferentes concentrações de nanolamelas para os diferentes parâmetros utilizados. A amostra com a variável mistura de solventes (MS) apresentou a maior concentração de material disperso e as amostras com o dobro de centrifugação (MSD, DC e MAD) exibiram as menores concentrações. As dispersões obtidas para os parâmetros do processo esfoliativo padrão individual e simultâneo (PI e PS), ultrassom de ponta (UP) e agitação magnética (AM) apresentaram concentrações de nanolamelas semelhantes.
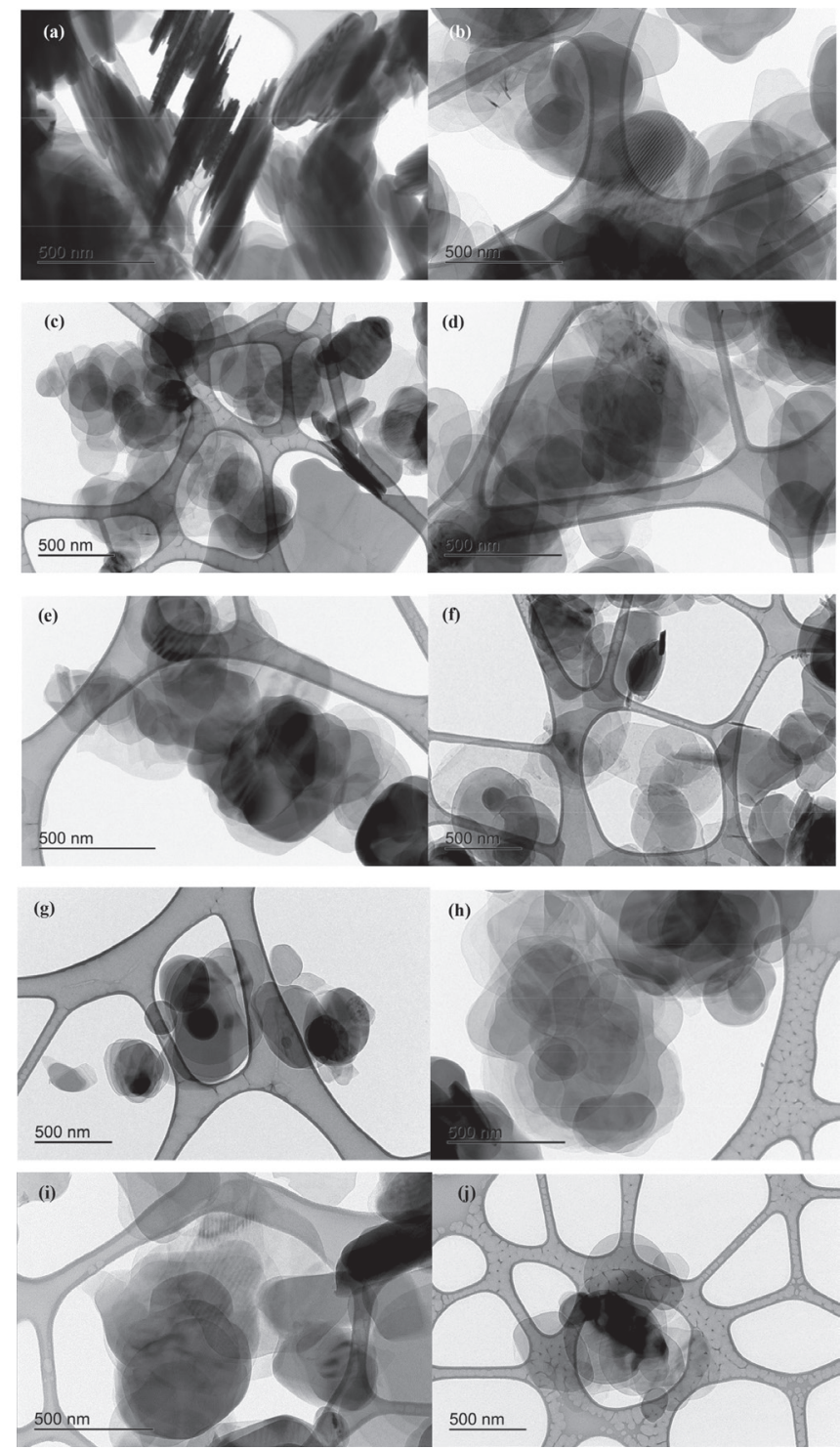

Figura 6. Imagens MET do h-BN micrométrico e das nanolamelas de BN esfoliadas por diferentes processos. (a) h-BN não esfoliado; (b) amostra padrão individual - PI; (c) padrão simultâneo - PS; (d) ultrassom de ponta - UP; (e) mistura de solventes - MS; $(f)$ dobro de centrifugação - DC; $(g)$ mistura de solventes e dobro de centrifugação - MSD; (h) agitação magnética - AM; (i) mistura de solventes e agitação-MSA; e, (j) mistura de solventes, agitação e dobro de centrifugação $-M A D$

Comparando a quantidade de material esfoliado obtida pela curva de calibração com a obtida por pesagem após a volatilização do solvente, nota-se que as amostras com as maiores quantidades de nanolamelas foram aquelas produzidas com as variáveis mistura de solvente (MS) e agitação magnética (MSA e AM), e a quantificação por absorbância apresentou um valor superior de, aproximadamente, $50 \%$ em relação à quantificação pelo material esfoliado seco. Vale ressaltar que certa diferença entre os valores de quantificação pelos dois processos avaliados é esperada, visto que há maior manipulação da amostra no caso da evaporação do solvente, podendo levar a maiores perdas de material em frascos, pipetas, etc. Nesta questão, quanto menor for a massa de material a ser medida, mais significativa será essa perda. Devido a isso, espera-se que a quantificação pela curva de calibração seja mais precisa. Além disso, no caso das amostras que foram esfoliadas com a mistura de solventes, o processo de evaporação foi mais lento e provavelmente as nanolamelas foram 
Tabela 2. Massa das dispersões esfoliadas de h-BN pela quantificação na absorbância UV-Vis e pelo material seco esfoliado, após evaporação do solvente

\begin{tabular}{|c|c|c|c|c|}
\hline \multirow{2}{*}{ Amostra } & \multirow{2}{*}{ Sigla } & \multicolumn{2}{|c|}{ Concentração material esfoliado } & \multirow{2}{*}{$\begin{array}{l}\text { Rendimento pela } \\
\text { absorbância }\end{array}$} \\
\hline & & Abs. $400 \mathrm{~nm}(\mathrm{mg})$ & Material seco (mg) & \\
\hline Padrão individual & PI & 7,1 & 7,1 & $7,1 \%$ \\
\hline Padrão simultâneo & PS & 5,0 & 5,7 & $5,0 \%$ \\
\hline Ultrassom de ponta & $\mathbf{U P}$ & 7,3 & 5,3 & $7,3 \%$ \\
\hline Mistura IPA:água & MS & 12,5 & 5,8 & $12,5 \%$ \\
\hline Dobro de centrifugação & DC & 0,5 & 2,2 & $0,5 \%$ \\
\hline Mist. IPA:água+dobro centrif. & MSD & 1,4 & 1,5 & $1,4 \%$ \\
\hline Agitação magnética & $\mathbf{A M}$ & 7,7 & 4,1 & $7,7 \%$ \\
\hline Mist. IPA:água+agitação & MSA & 9,5 & 5,1 & $9,5 \%$ \\
\hline Mist. IPA:água+agit.+dobro cent. & MAD & 0,1 & 0,8 & $0,1 \%$ \\
\hline
\end{tabular}

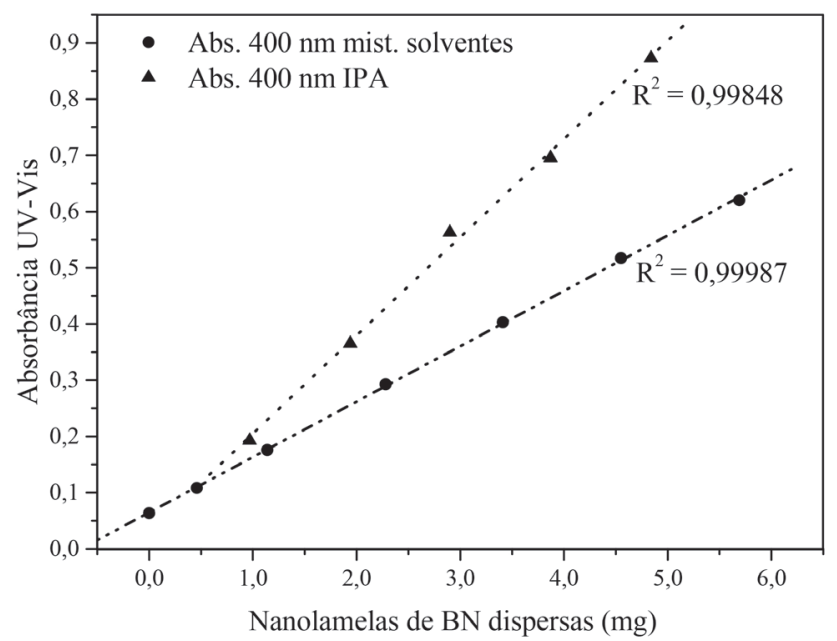

Figura 7. Curva de calibração das dispersões de nanolamelas de BN em álcool isopropílico (IPA) e na mistura de solventes (20\% de IPA em água) versus a intensidade da absorbância em $400 \mathrm{~nm}$

arrastadas pela água em evaporação, levando ainda a maiores perdas de material e contribuindo para a diferença observada.

As amostras esfoliadas pelo processo padrão (PI e PS) e com o auxílio do ultrassom de ponta (UP) apresentaram resultados similares e com grande condordância entre os dois métodos de quantificação. Já as amostras preparadas com o dobro de centrifugação (DC, MSD e MAD) exibiram os menores rendimentos. Analisando a última coluna da Tabela 2, os resultados indicaram que a mistura de solventes foi a variável que permitiu o maior aumento no rendimento do processo e o dobro de centrifugação, a maior redução.

Observa-se, de um modo geral, que a obtenção de nanolamelas bidimensionais de nitreto de boro pode ser vastamente explorada com a técnica de esfoliação líquida pela combinação de solventes com a ultrassonificação e centrifugação, não exigindo equipamentos nem processos complexos. No entanto, depende da otimização dessas variáveis. O uso combinado de ultrassom (ponta e banho) não apresentou aumento no rendimento do processo esfoliativo e, apesar de discordar com o conceito de que o aumento do tempo de ultrassom gera partículas melhor esfoliadas, ${ }^{28}$ reitera o conceito de distribuição de tamanhos comum na esfoliação dos materiais lamelares. ${ }^{20}$ A centrifugação demonstrou grande interferência no rendimento do processo, pois a separação de nanolamelas mais ou menos esfoliadas está estritamente vinculada com a rotação do equipamento e interfere no rendimento da técnica que, aliás, ainda é limitado em escalas laboratoriais.

\section{CONCLUSÃO}

O trabalho explorou a interferência de diferentes parâmetros no processo esfoliativo do nitreto de boro hexagonal em meio líquido e demonstrou que a escolha do solvente é crucial para o rendimento do processo, baseado em uma tensão superficial ótima do sistema solvente-soluto. As imagens de MET das amostras esfoliadas comprovaram que as partículas tridimensionais de h-BN foram esfoliadas em lamelas 2D de uma e várias camadas e com dimensões laterais semelhantes. A principal diferença observada entre as diferentes rotas esfoliativas foi em relação ao parâmetro de dobro de centrifugação (DC), que apresentou menores espessuras de partícula e rendimento.

A quantificação pela absorbância no UV-Vis demonstrou que as dispersões preparadas com o dobro de centrifugação (DC) retêm menor quantidade de nanolamelas esfoliadas no sobrenadante e que as amostras esfoliadas com a mistura de solventes (MS) possuem as maiores concentrações.

Considerando as caracterizações realizadas, a metodologia e o tempo de preparo de cada processo de esfoliação, as variáveis mais eficazes foram o padrão simultâneo (PS) e a mistura de solventes (MS), as quais podem ser associadas em um único processo esfoliativo. O dobro de centrifugação é uma variável a ser considerada, pois é o processo que retém as lamelas mais esfoliadas, podendo ser relevante dependendo da aplicação final das nanolamelas obtidas. Em síntese, o processo esfoliativo mais promissor foi a dispersão de h-BN em pó na mistura de solventes (20\% IPA em água) durante $3 \mathrm{~h}$ no ultrassom, seguido de centrifugação à 1500 ou 3000 rpm.

\section{AGRADECIMENTOS}

Os autores agradecem à UFPR, COPEL, aos Institutos LACTEC e à ANEEL pelo suporte finaceiro; ao CNPq pelo benefício da lei 8010/90 e ao Professor Doutor Aldo José Zarbin, do Departamento de Química da Universidade Federal do Paraná, pelo apoio no desenvolvimento do trabalho.

\section{REFERÊNCIAS}

1. Zhang, H.; ACS Nano 2015, 9, 9451.

2. Yaya, A.; Agyei-Tuffour, B.; Dodoo-Arhin, D.; Nyankson, E.; Annan, E.; Konadu, D. S.; Sinayobye, E.; Baryeh, E. A.; Ewels, C. P.; Global Journal of Engineering, Design \& Technology. 2012, 1, 32.

3. Nicolosi, V.; Chhowalla, M.; Kanatzidis, M. G.; Strano, M. S.; Coleman, J. M.; Science (Washington, DC, U. S.). 2013, 340, 1226419.

4. Coleman, J. N.; Lotya, M.; O’Neill, A.; Bergin, S. D.; King, P. J.; Khan, U.; Young, K.; Gaucher, A.; De, S.; Smith, R. J.; Shvets, I. V.; Arora, S. 
K.; Stanton, G.; Kim, H.; Lee, K.; Kim, G. T.; Duesberg, G. S.; Hallam, T.; Boland, J. J.; Wang, J. J.; Donegan, J. F.; Grunlan, J. C.; Moriarty, G.; Shmeliov, A.; Nicholls, R. J.; Perkins, J. M.; Grieveson, E. M.; Theuwissen, K.; Mccomb, D. W.; Nellist, P. D.; Nicolosi, V.; Science (Washington, DC, U. S.) 2011, 331, 568.

5. Butler, S. Z.; Hollen, S. M.; Cao, L.; Cui, Y.; Gupta, J. A.; Gutiérrez, H. R.; Heinz, T. F.; Hong, S. S.; Huang, J.; Ismach, A. F.; JohnstonHalperin, E.; Kuno, M.; Plashnitsa, V. V.; Robinson, R. D.; Ruoff, R. S.; Salahuddin, S.; Shan, J.; Shi, L.; Spencer, M. G.; Terrones, M.; Windl, W.; Goldberger, J. E.; ACS Nano 2013, 7, 2898.

6. Taha-Tijerina, J.; Narayanan, T. N.; Gao, G.; Rohde, M.; Tsentalovich, D. A.; Pasquali, M.; Ajayan, P. M.; ACS Nano 2012, 6, 1214.

7. Golberg, D.; Bando, Y.; Huang, Y.; Terao, T. Mitome, M.; Tang, C.; Zhi, C.; ACS Nano. 2010, 4, 2979.

8. Lin, Y.; Connell, J. W.; Nanoscale 2012, 4, 6908.

9. Wang, Y.; Shi, Z.; Yin, J.; J. Mater. Chem. 2011, 21, 11371.

10. Meziani, M. J.; Song, W.; Wang, P.; Lu, F.; Hou, Z.; Anderson, A.; Maimaiti, H.; Sun, Y.; ChemPhysChem 2015, 16, 1339.

11. Niu, L.; Coleman, J. N.; Zhang, H.; Shin, H.; Chhowalla, M.; Zheng, Z.; Small 2016, 12, 272.

12. Geim, A. K.; Novoselov, K. S.; Nat. Mater. 2007, 6, 183.

13. Lin, Z.; Mcnamara, A.; Liu, Y.; Moon, K. S.; Wong, C. P.; Compos. Sci. Technol. 2014, 90, 123.

14. Marsh, K. L.; Souliman, M.; Kaner, R. B.; Chem. Commun. (Cambridge, U. K.). 2015, 51, 187

15. Cao, L.; Emami, S.; Lafdi, K.; Mater. Express. 2014, 4, 165.

16. Rafiei-Sarmazdeh, Z.; Jafari, S. H.; Ahmadi, S. J.; Zahedi-Dizaji, S. M.; J. Mater. Sci. 2016, 51, 3162.
17. Bao, J.; Jeppson, K.; Edwards, M.; Fu, Y.; Ye, L.; Lu, X.; Liu, J.; Electron. Mater. Lett. 2016, 12, 1.

18. Zhi, B. C.; Bando, Y.; Tang, C.; Kuwahara, H.; Golberg, D.; Adv. Mater. (Weinheim, Ger.) 2009, 21, 2889.

19. Ma, P.; Spencer, J. T.; J. Mater. Sci. 2014, 50, 313.

20. Kouroupis-Agalou, K.; Liscio, A.; Treossi, E.; Ortolani, L.; Morandi, V.; Pugno, N. M.; Palermo, V.; Nanoscale 2014, 6, 5926.

21. Halim, U.; Zheng, C. R.; Chen, Y.; Lin, Z.; Jiang, S.; Cheng, R.; Huang, Y.; Duan, X.; Nat. Commun. 2013, 4, 1.

22. Morishita, T.; Okamoto, H.; Katagiri, Y.; Matsushita, M.; Fukumori, K.; Chem. Commun. (Cambridge, U. K.) 2015, 51, 12068.

23. Hernandez, Y.; Nicolosi, V.; Lotya, M.; Blighe, F. M.; Sun, Z.; De, S.; Mcgovern, I. T.; Holland, B.; Byrne, M.; Gun'Ko, Y. K.; Boland, J. J.; Niraj, P.; Duesberg, G.; Krishnamurthy, S.; Goodhue, R.; Hutchison, J.; Scardaci, V.; Ferrari, A. C.; Coleman, J. N.; Nat. Nanotechnol. 2008, 3, 563.

24. Zhou, K. G.; Mao, N. N.; Wang, H. X.; Peng, Y.; Zhang, H. L.; Angew. Chem., Int. Ed. 2011, 50, 10839.

25. Cunningham, G.; Lotya, M.; Cucinotta, C. S.; Sanvito, S.; Bergin, S. D.; Menzel, R.; Shaffer, M. S. P.; Coleman, J. N.; ACS Nano 2012, 6, 3468.

26. Lin, Y.; Williams, T. V.; Connell, J. W.; J. Phys. Chem. Lett. 2010, 1, 277.

27. Han, W. Q.; Wu, L.; Zhu, Y.; Watanabe, K.; Taniguchi, T.; Appl. Phys. Lett. 2008, 93, 223103.

28. Durge, R.; Kshirsagar, R.V.; Tambe, P.; Procedia Eng. 2014, 97, 1457.

29. Rathod, N.; Hatzikiriakos, S. G.; Polym. Eng. Sci. 2004, 44, 1543.

30. Khan, U.; O'Neill, A.; Porwal, H.; May, P.; Nawaz, K.; Coleman, J. N.; Carbon 2012, 50, 470. 